\title{
CAPITAL SOCIAL E A CULTURA: UM ESTUDO SOBRE AS POSSÍVEIS RELAÇÕES
}

\author{
Edineide Maria de Oliveira ${ }^{1}$ \\ Karine Freitas Sousa ${ }^{2}$
}

\section{RESUMO}

Este estudo abordou as relações entre o capital social e a cultura, sob a perspectiva dos autores James Coleman, Maria Celina D'Araujo, Robert Putnam, Zygmunt Bauman. A questão em foco tratou superficialmente da política na visão de Montesquieu e Tocqueville e questionou se esse seria um indicativo relativo ao capital social, cuja forma de organizar uma sociedade implica na capacidade de formação deste capital social baseado em relações de confiança e reciprocidade que se relaciona com a cultura. Uma breve análise recaiu sobre como a cultura e as relações políticas contribuem para a composição do capital social, contando com uma pesquisa bibliográfica fundamentada nos autores citados.

PALAVRAS-CHAVE: Capital Social; Cultura; Política.

\begin{abstract}
This study deals with the relations that social capital has with culture, from the perspective of the authors James Coleman, Maria Celina D'Araujo, Robert Putnam, Zygmunt Bauman. The question focused on politics in the view of Montesquieu and Tocqueville and questioned whether this would be an indication of social capital, whose way of organizing a society implies the ability to form this social capital based on relationships of trust and reciprocity. A brief analysis fells on how the culture and the political relations contribute to the composition of social capital, counting on a bibliographical research based on the mentioned authors.
\end{abstract}

KEY-WORDS: Capital Stock; Culture; Policy.

\footnotetext{
${ }^{1}$ Economista e doutora em Ciências Sociais pela PUC SP; coordenadora e professora de Administração Economia no UNIFAI - Centro Universitário Assunção.

${ }^{2}$ Doutora em Ciências Sociais pela PUC SP e professora titular na UFBA.
} 


\section{INTRODUÇÃO}

O presente estudo pretende abordar as relações entre o capital social e os axiomas sociais, com destaque para a cultura. O capital social desempenha um papel fundamental nessa dinâmica, e é importante verificar a forma como esse capital é adquirido e como ele atua em determinadas esferas. Para tanto, este artigo apresentará os conceitos de capital social de renomados teóricos que buscam expandir certas definições e conceitos acerca do capital social na atualidade. Também mostrará as relações do capital social com a cultura de acordo com os autores James Coleman, Maria Celina D’Araujo, Robert Putnam, Zygmunt Bauman, Terry Eagleton, Pierre Bourdieu.

Apesar de o conceito de capital social não ser novo - seu registro remonta a 1890 - o mesmo ganhou notoriedade na década de 1990 e passou ser discutido com maior ênfase na academia e relacionado com outras áreas e outros capitais. Por isso, foi necessário um recorte cujo eixo de estudo foi pautado na relação entre o capital social e a cultura.

Ferragina (2010) ressaltou que Alexis de Tocqueville, no intuito de discutir a organização da sociedade americana, destacou a importância do capital social em virtude da união de pessoas, formando grupos de interesses que contribuíram para a participação social e consequentemente para a promoção da igualdade de condições, porque:

Para que os homens permaneçam ou se tornem civilizados é necessário que, entre eles, a arte de se associar se desenvolva e se aperfeiçoe na mesma proporção que a igualdade de condições (TOCQUEVILLE apud FERRAGINA, 2010, p.136).

Partindo da política na visão de Montesquieu e Tocqueville, como um indicativo pertencente ao capital social, este trabalho está organizado primeiramente com os conceitos de capital e sua origem, destacando a economia em Adam Smith e a sociologia em Karl Marx. Em seguida, é apresentado o conceito de capital social e os principais autores que tratam de sua importância. Foram identificadas as relações entre capital social e cultura e, na sequência, as especificidades entre o capital social e a cultura política. Nas considerações finais, o estudo apresenta as perspectivas para os desdobramentos da pesquisa sobre capital social.

\section{Conceitos de capital}

A noção de capital remonta à teoria econômica a partir da publicação do livro "A Riqueza das Nações", de Adam Smith, em 1776, na Inglaterra. Nesta obra, Smith demonstra que os fatores de produção como terra, trabalho e capital são imprescindíveis para o crescimento econômico de uma nação. É enaltecido em seu livro o capital produtivo representado por máquinas, ferramentas e equipamentos utilizados na produção de outros bens e serviços, possibilitando a interação entre 
capitais naturais e o capital humano ${ }^{3}$, precisamente o esforço físico dos trabalhadores para transformar as matérias primas em um produto acabado (GASTALDI, 2006).

Para Dowbor (2003), o conceito "de capital" aproxima-se com "riqueza", sendo esta representada pela acumulação de bens econômicos provinda da maximização do lucro, objetivo do sistema capitalista. Entretanto, é pertinente fazer a distinção entre riqueza individual e a riqueza da nação. O capital produtivo, que é baseado no aumento da produção, é tangível e difere do capital especulativo, que é intangível e opera na volatividade das finanças - porém, ambos compõem a riqueza de um País. Da mesma forma, o capital individual, aquele que consiste na força de um único trabalhador em sua função, e que pode ser contemplado como capital humano, também dará sua contribuição à riqueza da nação.

Todavia, existem outras nomenclaturas para o termo capital, como os ativos intangíveis, utilizados na contabilidade: capital constante, variável, fixo, aberto, fechado. No lado social, destacam-se neste estudo o capital cultural e o capital social.

A partir dos anos 90 o Banco Mundial divulgou uma nova distinção para os capitais intangíveis: capital natural, que se refere aos recursos naturais que um país possui; capital financeiro, relacionado à produção da sociedade, mas contabilizado em valor monetário; capital humano, aquele que faz referência ao que o indivíduo sabe fazer de acordo com seu conhecimento, habilidades e competências e; por fim, o capital social, que, de acordo com Araujo (2003, p: 11), é designado como o que "mostra a capacidade que uma sociedade possui em estabelecer laços de confiança interpessoal e redes de cooperação com vista à produção de bens coletivos".

Para Araujo (2003), nas ciências sociais, o conceito de capital é complexo e controverso. Historicamente, o conceito de capital para Karl Marx mostra a mais valia gerando excedente por parte do trabalhador, e evidencia que o mesmo não é remunerado pelo capitalista na sua totalidade.

Observa-se que tanto para Adam Smith como para Karl Marx, o capital social se faz presente, pois é composto de relacionamentos e laços de confiança no ambiente de trabalho, na família, na escola ou em outros grupos da sociedade.

\section{Conceito de Capital Social}

\footnotetext{
${ }^{3}$ Capital Humano é um termo administrativo, econômico e sociológico que se refere à riqueza que se pode ter em uma fábrica, empresa ou instituição em relação à qualificação dos seus funcionários. Essa riqueza, no caso, é entendida como conhecimento, habilidades e atitudes - CHA
} 
O capital social se compõe pela rede de relações interpessoais que cada indivíduo constrói, com os benefícios ou malefícios que ela pode gerar na competição entre os grupos humanos. Este conceito também está relacionado com o capital cultural, conforme elucida Pierre Bourdieu ${ }^{4}$, e desse modo o capital social é diferente do capital humano. Este último, porém, possui uma certa sujeição que colabora nas atividades desempenhadas pelo indivíduo no seu grupo e assim pode interferir nas relações de trabalho.

Destaca-se como o primeiro grupo de relacionamento o familiar, onde os laços são mais fortes e têm uma duração maior. E o fator tempo, em Granovetter, (1983), é o que possibilita diferenciar os grupos, mas a relação deverá ser alimentada pela emoção, intimidade, confiança e reciprocidade para compor uma rede intitulada capital social.

De acordo com o Banco Mundial é importante que o capital social seja permeado de leis e regras para a normalidade das instituições e da sociedade. Quando, porém, atuam as ditaduras, estas depredam a sociedade civil e prejudicam o capital social nos quesitos liberdade de expressão e desenvolvimento socioeconômico que caracterizam as sociedades democráticas.

Dessas acepções sobressaem estudiosos do capital social, como os americanos James Coleman no final da década de 1980 e Robert Putnam, cuja crença estipula que um conjunto de práticas sociais, normas e relações de confiança promovem o capital social.

Para Putnam (2002, p: 13), “o capital social diz respeito às características da organização social como confiança, normas e sistemas que contribuam para aumentar a eficiência da sociedade, facilitando as ações coordenadas." Ao mesmo tempo, Araujo (2003) afirma que a sociedade deverá possuir laços de confiança e de cooperação na busca do bem comum.

No entanto, Pierre Bourdieu, que usou o termo em 1972, em seu Esboço de uma teoria da prática, escreveu que "o capital social é um agregado de recursos atuais ou potenciais, vinculados à posse de uma rede duradoura de relações de familiaridade ou reconhecimento mais ou menos institucionalizadas" (BOURDIEU, 1998, p.13 ).

Assim, para Bourdieu (1998), a família tem um vínculo que pode ser considerado socialmente constituído e para sempre. Observa-se que também precisa de laços de confiança, ou seja, é necessária a manutenção das relações para a produção de capital social. Por outro

${ }^{4}$ Em sua obra "O Capital Social". 
lado, as mudanças de geração proporcionam uma diferenciação nas relações que dificulta o capital social.

Existe convergência entre os conceitos no tocante a organização social e as normas que podem ser institucionalizadas para aumentar a eficiência da sociedade, e que, na perspectiva de Putnam (2002), promove a democracia, porém existe divergência no âmbito das características da organização, e não de um indivíduo e sua família, que terão necessariamente confiança e reciprocidade entre si, pois a confiança é um atributo de extrema importância para o capital social.

Em Coleman, 1994, o capital social dependerá da ação individual das pessoas para fazer sentido na organização da sociedade e para tanto deverá estar embasado em uma rede de trocas em que preponderam a confiança e também a reciprocidade.

Já que o capital social está diretamente relacionado com a parte econômica e política, é necessário pontuar que esses campos de relacionamentos são compostos de redes formadas por grupos de pessoas que têm interesse comum, convergindo, assim, com a postura de Coleman no sentido das trocas e também de Putnam na busca de uma democracia, na confiança e reciprocidade.

Higgins (2005) utiliza-se da obra de Pierre Bourdieu para sinalizar que o capital social é um ativo intangível, e possui uma dimensão ampla que permeia a sociedade, porém, nas relações de trocas, se destaca o capital econômico, com proeminência ao dinheiro e ao direito de propriedade. Evidencia ainda a concepção de James Coleman quanto à estrutura social em que um grupo de pessoas consegue se reunir para que todos os sujeitos individualmente cumpram as suas metas de acordo com os respectivos interesses.

No entanto, é importante salientar que, para que haja as trocas justas, cooperação, reciprocidade e confiança em uma rede de relacionamentos, é necessária a presença de uma cultura que privilegie essas práticas dentro de uma sociedade e que deverá ter consequências na política.

\section{Capital Social e cultura}

Segundo Araujo (2003), o capital social está relacionado nas ciências sociais, enquanto que o capital humano está inserido nas ciências sociais aplicadas, especificamente nas ciências econômicas e administrativas, porém ambos são ativos intangíveis. O termo capital social é antigo, todavia, foi mais evidente no século XX, e deverá, segundo Araujo (2003), ser usado para promover uma sociedade justa e melhor, com destaque para o desenvolvimento socioeconômico, ou seja, contribuindo com o governo e todas as esferas da sociedade na busca de um índice de desenvolvimento humano (IDH) melhor, compatível com uma economia de primeiro mundo. Dados divulgados pelo Programa das 
Nações Unidas para o Desenvolvimento (Pnud) mostram que o IDH do Brasil passou de 0,752 em 2013 para 0,755 em 2014. Apesar do aumento, o Brasil caiu uma posição no ranking mundial de desenvolvimento humano e passou a ocupar o $79^{\circ}$ lugar entre 188 países em 2017.

Neste estudo, relaciona-se capital social à cultura. Segundo Bauman (2005), existem diferenças da cultura como conceito hierárquico, a cultura como conceito diferencial e o conceito genérico de cultura. Disso decorre que a cultura de cada local compõe o capital social da comunidade, em que as relações sociais pertencem a uma determinada estrutura social. No entanto, Bauman (2002) não traz um conceito de cultura pronto e sim uma reflexão do conceito de cultura de diversos autores, mostrando que o conceito de cultura por ele escolhido é pela "teoria do uso", ou seja, aquela que tenta elucidar o significado de "elementos linguísticos semanticamente carregados pelo estudo dos locais em que aparecem tanto na dimensão paradigmática quanto na sintagmática” (BAUMAN, 2012, p:87).

Para demonstrar uma reflexão sobre o tema, Bauman (2005) faz menção a diversos autores que conceituam cultura, caso de A. Kroeber e C. Kluckhohn, que dividiram em seis grupos as definições de cultura, e dos antropólogos anglo-saxões, que registraram os modos estranhos de vida em via de extinção. Os estudos de Bauman (2005) mostram experiências relatadas por outros autores quanto à forma como os antropólogos realizaram suas experiências e, ainda, como americanos e britânicos tinham maneiras diferentes de verificar a cultura de cada comunidade: os americanos trabalhavam com línguas, artefatos, indivíduos sobreviventes; os britânicos utilizavam o método da observação.

Com relação à ideia de cultura, Eagleton, (2005) mostra que o conceito também é amplo. O autor faz uma reflexão, organizada em cinco capítulos, acerca das versões de cultura; cultura em crise; guerras culturais; cultura e natureza e rumo a uma cultura comum, abordando: aspectos culturais, tempo histórico e evolutivo, conceito de cultura e suas diversas versões, a qual tem uma relação direta com o capital social, em que cada sociedade consegue formar laços culturais que na maioria das vezes são pautados de relações de confiança.

Eagleton (2005) afirma que "Cultura" é uma questão do desenvolvimento total e harmonioso da personalidade, mas ninguém pode realizar isso sozinho; seu desenvolvimento tende a vir de influências sociais que podem envolver até questões políticas. Diante desse conceito, verifica-se o quanto de capital social existe relacionado com a cultura, pois a união de pessoas promovidas por vínculos sociais, derivados da família, amizade e relações profissionais é componente imprescindível do capital social. 
No entanto, Eagleton (2005) ressalta a importância de viver para cultura e também viver da cultura, visto que esta faz parte de um contexto macroeconômico, onde existem hábitos, costumes, regras, trocas, trabalho e necessidades, promovendo o dinamismo característico de uma sociedade. A cultura é formada de pessoas para pessoas, formando redes de relacionamentos possibilitando a composição do capital social (EAGLETON, 2005).

Assim, no contexto, cultura e sociedade estão imbricadas. Não obstante, a cultura não está nem dissociada da sociedade nem completamente de acordo com ela. A cultura é justamente o mecanismo daquilo que mais tarde será chamado "hegemonia", moldando os sujeitos humanos às necessidades de um novo tipo de sociedade politicamente organizada, remodelando-os com base nos agentes dóceis, moderados, de elevados princípios, pacíficos, conciliadores e desinteressados dessa ordem política (EAGLETON, 2005).

De acordo com o autor, a Cultura precisa ser vivenciada, ou seja:

Cultura não é unicamente aquilo que vivemos. Ela também é em grande medida aquilo o que vivemos. Afeto, relacionamento, memória, parentesco, lugar, comunidade, satisfação emocional, prazer intelectual, um sentido de significado do último: tudo isso está mais próximo, para a maioria de nós, do que cartas de direitos humanos ou tratados do comércio (EAGLETON, 2005, p: 41).

Segundo Eagleton, a cultura pode ficar também desconfortavelmente próxima demais. Essa própria intimidade pode tornar-se mórbida e obsessiva a menos que seja colocada em um contexto político esclarecido, um contexto que possa temperar essas imediações com aflições mais abstratas, mas também de certa forma mais generosas, possibilitando a reciprocidade e a cooperação, elementos essenciais para o capital social.

Putnam (1998) buscou entender a disparidades de desenvolvimento entre o norte e sul da Itália; no Norte da Itália é visível um associativo para o lazer e de outras atividades, destacando a facilidade de as pessoas cooperarem e confiarem no governo, nos vizinhos, criando assim laços, ou seja, relacionamentos positivos. Desse modo, este local demonstrava maior presença de capital social que permitia um desenvolvimento socioeconômico, porém, é importante ratificar que a cultura, segundo Eagleton, é tudo aquilo "para que vivemos e de que vivemos".

Neste sentido, Araujo (2003, p:19) pontua os principais fatores do capital social: 
O capital social está definido por três fatores interrelacionados: confiança, normas e cadeias de reciprocidade e sistema de participação cívica - sistema que permitem às pessoas cooperar, ajudar-se mutuamente, zelar pelo bem público, promover a prosperidade.

Para Araujo (2003), a prosperidade de um país ou de uma comunidade dependerá do capital social e da cultura. Completando, Fukuyama (1996) acredita que a economia está permeada pela cultura e dependente do capital social que, para o autor, constitui valores morais e de confiança.

Ainda de acordo com Araujo (2003), a cultura é o instrumento mais importante do que o capital físico no mundo globalizado no tocante à verificação das vantagens e desvantagens econômicas. Os valores culturais ajudam a promover o desenvolvimento econômico do local, principalmente se as relações forem permeadas de coletivismo e parentesco. Como exemplos, temos Lima, no Peru, El Salvador e Guatemala, onde se verificaram experiências bem sucedidas de resgate dos valores culturais e promoção da autoestima entre a população que vivia em miséria absoluta, e, como resultado, observou-se geração de riqueza.

Segundo Fukuyama (1996), o desenvolvimento econômico é um objetivo de política macroeconômica, que ganhou notoriedade no debate nos últimos 20 anos, com início praticamente depois da Segunda Guerra Mundial. Geralmente é confundido com o crescimento. A teoria do desenvolvimento econômico mostra a diversidades de questões que podem ser eliminadas com políticas de desenvolvimento socioeconômico sustentável. Contudo, não depende apenas da acumulação de capital e crescimento do PIB, mas de uma distribuição de renda que proporcione melhoria das condições de vida para a sociedade como um todo, e aí entra o conceito de cultura relacionada ao capital social em nome da prosperidade de uma nação.

A cultura propicia as relações que podem ser de confiança ou não, pois, segundo Bauman (2005), o homem é o único ser que pode desafiar sua realidade e reivindicar um significado mais profundo no tocante a organização da sociedade, especificamente no âmbito da justiça, da liberdade e nas relações que se materializam no coletivo.

\section{Capital social e a cultura política}

A composição do capital social é realizada por uma sociedade e sua cultura. A sociedade precisa estar organizada socialmente, economicamente, juridicamente e politicamente. Neste sentido, segundo Araújo (2003): 
Montesquieu foi talvez o primeiro cientista político a partilhar seriamente de uma postura política relativista quando da análise dos governos e suas formas. Ou seja, é antiga a ideia de que instituições políticas não são arranjos formais independentes dos contextos em que operam (ARAUJO, 2003 p. 41).

O capital social será formado de acordo com as instituições políticas que deverão contribuir para uma cultura política, organizada de acordo com uma estrutura social que, segundo Montesquieu, e que Araujo (2003) concorda, gerenciará a conduta dos indivíduos por meio de um conjunto de regras de ordenamento da vida social.

A partir desses levantamentos, observa-se que a cultura política tende a ser autoritária quando há divisões e centralização de poder, e isso impacta de certa forma o capital social que, no caso, passa a ser composto de relações de interesses políticos principalmente. No entanto, dependendo da forma de governo mostrada por Montesquieu (1973), a saber, monarquia, república e despotismos, o capital social será diferente. Na monarquia, regime que na concepção de Montesquieu (1973) é o mais adequado para promover o equilíbrio entre os poderes e, portanto, promover a estabilidade política, se formam relações de confiança e reciprocidade entre os poderes executivo, legislativo e judiciário.

A república por sua vez é o regime pautado na virtude política, que não precisa ser estritamente moral, mas sim um respeito às regras, normas e leis, buscando manter um panorama de harmonia e contribuição para o bem comum, em que a coletividade é favorecida. Por fim, o despotismo é baseado no medo, no cuidado, e na cautela para não infringir o bom andamento da sociedade. Esse regime é o mais autoritário, pois o povo, por medo ou falta de conhecimento, delega todos os poderes a uma autarquia ou oligarquia.

Putnam (1996) concorda com Tocqueville (1977) que a democracia se fortalece quando a sociedade civil se tonifica. Assim, para a formação de um capital social que busca o desenvolvimento socioeconômico, são necessárias instituições políticas, organizadas e legitimadas, pois, caso contrário, a vida em sociedade se tornaria inviável ao sistema econômico. Como proposto por Tocqueville (1977), a democracia é uma nova forma de organização social, não só mudança de regime político. Resumidamente, para o autor, a democracia consiste no "desenvolvimento gradual e progressivo da igualdade", permitindo a todos e a cada um, independentemente de diferenças hereditárias e de desigualdade de fortuna, atingir o bem-estar comum, graças especialmente à aquisição de riquezas materiais (Gibert, 1977, p. 17). 
Portanto, segundo Tocqueville (1977), a sociedade civil precisa se organizar e formar associações de caráter político, moral ou intelectual, na busca de uma cultura cívica ${ }^{5}$ e liberdade para assim conquistar um capital social pautado em relações de confiança, buscando a igualdade e liberdade.

\section{Considerações finais}

O capital social está presente nas relações, sejam elas de amizades, familiares, trabalhos e outras relações que buscam promover redes de relacionamento pautadas na confiança. No entanto, na visão de autores considerados importantes, o capital social está contido na sociedade e principalmente porque tem uma relação direta com a cultura, pois não existe capital social sem cultura e nem cultura sem capital social.

Entretanto, a relação não está somente elencada com a cultura, mas também com a política. Como mostram os escritos de Montesquieu e Tocqueville, é a forma de organização da sociedade que vai possibilitar a formação do capital social, que, por sua vez, deverá ser pautado nas relações de confiança e permitir o êxito na busca de um desenvolvimento socioeconômico.

Verificou-se que o capital social é a busca constante em todas as sociedades desde a antiguidade. A dificuldade de fazer com que todos os envolvidos busquem o bem comum é uma tarefa árdua, principalmente no mundo considerado globalizado em que os interesses do capital, principalmente o financeiro, conseguem criar uma cultura do individualismo na busca de conseguir bens materiais e o prazer. A cultura de levar vantagem é muito forte, e se contrapõe à relação ganhaganha, em que o objetivo é a troca justa e a busca de satisfação coletiva. Nesse sentido, a cultura de levar vantagem em tudo é permissiva à formação do capital social.

Existem ferramentas tecnológicas como redes sociais, novos telefones celulares, a internet e outros mecanismos de relacionamento e estrutura política, porém o individualismo e a falta de

\footnotetext{
${ }^{5}$ Termo relacionado a Tocqueville, que na primeira metade do século XIX ficou maravilhado com o poder de associação e participação dos americanos. Foi nesse momento que ele analisou esse espírito associativo como "interesse bem-compreendido", ao ver que os americanos se organizavam em associações com objetivos e interesses comuns. Entretanto, o termo só entrou para agenda acadêmica nos anos 1960, e serviu para explicar a imensa quantidade de ditaduras que se formaram nesta época, principalmente na América Latina.
} 
urbanidade $^{6}$ são crescentes principalmente nas grandes capitais, impedindo a formação de capital social e o desenvolvimento da sociedade, pautada em uma cultura cívica.

Viver em sociedade, respeitar a cultura, participar ativamente das decisões de governo deveriam ser uma prática de todos os cidadãos, entretanto, a falta de confiança e reciprocidade faz com que as relações fiquem complicadas e não subsidiem a formação do capital social. É preciso promover relacionamentos amistosos e de confiança em qualquer ambiente. A cultura de valores sociais maximiza os resultados quando se busca o bem comum, independentemente de ser um objetivo de empresa ou de sociedade como um todo.

Apesar de contar com autores clássicos e suas obras com conteúdos agregadores para a organização da sociedade atual, este estudo limitou-se a tratar de uma reduzida reflexão acerca do capital social, da cultura social e da cultura política. É necessário expandir os conceitos e fazer uma reflexão mais aprofundada das relações do capital social com a cultura e a política, principalmente no Brasil.

\section{REFERÊNCIAS}

ARAUJO, Maria Celina Soares D', Capital social. Rio de Janeiro: Jorge Zahar Ed., 2003.

ARISTÓTELES. A Política. 2a ed. São Paulo: Martins Fontes, 1998.

BANCO MUNDIAL, Relatório sobre o Desenvolvimento Mundial 1992. Rio de Janeiro, Fundação Getúlio Vargas, 1993.

BAUMAN, Zygmunt. La cultura como praxis. Buenos Aires, Paidós, 2002.

BAUMAN, Zygmunt. Ensaios sobre o conceito de cultura. Tradução de Carlos Alberto Medeiros. Rio de Janeiro: Jorge Zahar Ed., 2005.

.Ensaios sobre o conceito de cultura. Tradução de Carlos Alberto Medeiros. Rio de Janeiro: Jorge Zahar Ed., 2012.

BOURDIEU, P. O capital social - notas provisórias. In: CATANI, A. \& NOGUEIRA, M. A. (Orgs.) Escritos de Educação. Petrópolis: Vozes, 1998.

\footnotetext{
${ }^{6}$ Urbanidade é um conjunto de formalidades e procedimentos que demonstram boas maneiras e respeito entre os cidadãos; afabilidade, civilidade, cortesia.
} 
COLEMAN, James Samuel. Foundations of Social Theory. Cambridge, Massachusetts, London, England: Belknap Harvard,1994.

DOWBOR, Ladislau. O que é capital. $2^{\circ}$ Ed. São Paulo: Cortez, 2003.

DURKHEIM, Émile. Sociologia. Organizador: José Albertino Rodrigues. São Paulo: Ática, 1999.

EAGLETON, Terry. A ideia de cultura. Tradução de Sandra Castello Branco. São Paulo: UNESP, 2005.

FERRAGINA, E. (2010) Social Capital and Equality: Tocqueville's Legacy. "The Tocqueville Review, vol. XXXI: 73-98" http:/ / www.emanueleferragina.com/ attachments/ 002_Ferragina\%20Tocqueville\%20review. Pdf

FUKUYAMA, Francis. Confiança: as virtudes sociais e a criação da prosperidade. Rio de Janeiro: Rocco, 1996.

GASTALDI, J.Petrelli, Elementos de economia política, 19º ed. São Paulo: Saraiva 2006.

GIBERT, P. Alexis de Tocqueville: Égalité sociale et liberté politique. Paris, Aubier Montaigne. 1977.

HIGGINS, Silvio Salej. Fundamentos Teóricos do Capital Social.Chapecó: Argos Ed. Universitária, 2005. 263 p.

IANNI, Octavio. (org.) Karl Marx: sociologia. 2a. ed. São Paulo: Editora Ática, 1980.

MONTESQUIEU, Barão de. Do espírito das leis. São Paulo: Abril Cultural, 1973. Coleção "Os pensadores", Vol. XXI.

PUTNAM, Robert D. Comunidade e Democracia: a Experiência da Itália Moderna. Rio de Janeiro: Ed. FGV, 1996.

SMITH, Adam. A riqueza das Nações. São Paulo: Nova Cultural. 1988. 